\title{
A Position Paper on the Implementation of Learning Technology Tools: Uncovering Faculty Perceptions
}

\author{
Zhanat Alma Elliston \\ Duke University, United States, zhanat.elliston@duke.edu
}

\begin{abstract}
Effective integration of learning technology tools in classrooms is a key component of 21 st century higher education classrooms. The goal of the position paper is to provide a discussion from the results of the research study and to uncover the faculty members' views and perceptions about implementing learning technology tools. Insights from this study revealed that it is a teaching technique and style of the faculty members in the use of these learning technology tools that determined the nature of their perception of success rather than the learning tools themselves.
\end{abstract}

Keywords: Learning technology, Classroom technology, Higher education, Faculty perceptions, Challenges of learning technology tools

\section{Introduction}

The goal of the position paper is to convey the results of the research study and provide with faculty members' perspectives regarding the implementation of the learning technology tools such as Cisco Spark and Microsoft Surface Hub smart whiteboard in the classrooms at one university. To begin, this position paper will describe the study, its research questions, the chosen methodology, and the data collection and analysis. Then, the core discussion of the position paper, however, will be on the emerged results of the study by uncovering the faculty member's opinions, the associated benefits and barriers, in order to support successful integration of the learning technology tools in the classrooms.

\section{The Study}

The lack of technological capacity in the classroom was identified as a need at the university. The university invested in the learning technology tools, it was the faculty's role to then use these tools to support learning. However, the implementation of these tools did not include information about the faculty's role, support, and involvement as stakeholders in the change process. Therefore, in order to understand the complexities of implementing learning technology tools, learning from the faculty's perceptions was essential to ensure the most effective implementation of learning technology tools in these classrooms.

The research questions were focused on exploring faculty members' perceptions about the main benefits and barriers of upgrading the university's classrooms with learning technology tools. Specifically, the first question addressed the faculty members' views and perceptions about the importance of implementing the Cisco Spark and Microsoft Surface Hub smart whiteboards in the classrooms. The second and third questions intended to discover the main benefits of and barriers of enhancing classroom experience by using learning technology tools respectively.

\section{Methodology}

A qualitative exploratory case study was chosen for this study. With the focus of this study on the stagnation in classroom technology innovation, the Technology Acceptance Model (TAM) framework (Davis, 1989) was used to explore faculty members' perceptions of the main benefits of and barriers to upgrading the local university's classrooms with active learning technology tools. Although the TAM has been widely used and known in technology acceptance research within a quantitative context, the framework has been increasingly used as the model for qualitative research in predicting user acceptance of emerging technology (Akgun, 2017; Cuhadar, 2014; Dube, 2017; Day et al., 2007; Hoppe, Steinhüser, \& Vogelsang, 2013; Ifenthaler \& 
Schweinbenz, 2016; Khalil, 2013; Karsh, Escoto, Beasley, \& Holden, 2006; Middlemass, Vos, \& Siriwardena, 2017; Salmona \& Kaczynski, 2016).

Based on Sarker and Wells's (2013) exploratory research study, the researchers provided an integrative view of the TAM framework that related to the assessment of experience that determined technology acceptance outcome. The TAM also has been redefined in response to technology acceptance discussions where it was often referred to as limited in its ability of predicting acceptance behaviors (Salmona \& Kaczynsko, 2016). In predicting adoption of technology, many researchers argued that it is also important to explore backgrounds and the human interaction between an individual and technology (Hoppe et al., 2013; Ouadahi, 2008; Salmona \& Kaczynsky, 2016; Sahin, 2008; Sahin \& Thompson, 2007; Serhan, 2019). Because quantitative studies used questionnaire-based surveys, the focus was mostly on statistical findings, not the interaction between individuals and technology (Hoppe et al., 2013; Wu, 2012).

Additionally, researchers often questioned the relevance of studies that relied on only quantitative data in the environment of relatively unexplored technology tools by suggesting that significant characteristics may easily be overlooked without taking qualitative data into account (Hoppe et al., 2013). However, these questions in quantitative studies were also viewed as strengths from a qualitative point of view (Hoppe et al., 2013; Salmona \& Kaczynski, 2016). Hoppe et al. (2013) analyzed the technology acceptance factors in-depth by looking into interaction between the individuals and technology. The authors used the TAM as a model in their qualitative research study to provide with an evidence that the TAM was "underrepresented" in qualitative research (Hoppe et al., 2013). As Holden and Karsh (2010) noted that TAM in qualitative studies can be informative and descriptive. Therefore, the TAM framework provided the means to explore the faculty perceptions about the implementation of the learning technology tools and to identify any associated and underlying factors.

\section{Context of the Study and Participants}

The focus of the research was only on one college with 1,234 undergraduate students, 976 graduate students, and 130 faculty members. A stratified strategy was used to ensure a proportional representation of faculty members from each department in the college. Two main criteria were used to select the participants for this study: 1) faculty actively teaching at least 1 to 2 classes per semester, and 2) each of the four departments of the college to have a representation proportional to the size of the department. Eight faculty members were recruited for the participation in this study. The sampling within the four departments was as follows:

Table 1. Sampling Representation from Four Departments

\begin{tabular}{ccccc}
\hline & Department 1 & Department 2 & Department 3 & Department 4 \\
& $(35)$ & $(20)$ & $(38)$ & $(40)$ \\
\hline Number of Participants (8) & 3 & 2 & 1 & 2 \\
\hline
\end{tabular}

\section{Data Collection and Analysis}

To collect data, the open-ended interview questions were developed to capture the views and perceptions of the faculty regarding redesigning the classrooms with learning technology tools. In constructing the study's interview instrument, the questions were also aligned with the theoretical framework for this study, Davis's (1989) TAM framework that proposes perceived usefulness (PU) and perceived ease of use (PEU) as two major factors affecting how users come to accept and use technology. PU is defined as "the degree to which a person believed that using a particular system would enhance his or her job performance," and PEU involves "the degree to which a person believes that using a particular system would be free of effort" (Davis, 1989, p. 320).

The interview questions that asked about the benefits of implementing the learning technology tools in classrooms focused on the usefulness and the perceived benefits of using the learning technology tools while the interview questions about barriers and obstacles of using learning technology tools in classrooms focused on the ease of use factors. To analyze the collected interview data, the interviews were transcribed, coded, and then analyzed for themes and patterns. An inductive data analysis approach helped with the development of themes and subthemes from the raw data (Thomas, 2003). The themes that emerged explained how the participants viewed and perceived the implementation of the learning technology tools in the classrooms. To support the findings from the inductive analysis, participants' direct quotes were selected to carry out the main theme or the elements of each subtheme. 


\section{Discussion}

Introducing learning technology tools to faculty might require them to acquire new skills and attend professional training. The faculty perception of using technology in classrooms was revealed by Weaver, Walker, and Marx (2012) who found that students "were ready to attack technology" without any formal training. Faculty, on the other hand, had the difficulty of maintaining proper training in basic software applications, had limited financial support to try and integrate technology in the classrooms as well as had constant challenges in identifying proper teaching methods that fit a lesson. A mixed study about faculty perceptions of using smart whiteboards that was conducted by Park (2014) revealed that implementation of smart whiteboards facilitated interaction between teachers and students and promoted student learning environment.

However, some of the already mentioned concerns such as training and sufficient technical support will still be required to effectively utilize new technology tools. Furthermore, in discussing some of the implications concerning the use of smart boards, Al-Qirim (2016) reported that integration of these smartboards in classrooms should be in "a peace-meal fashion" (p.1909) in a form of supplementing existing parts of teaching approaches and strategies, in which, the adoption and usage of the smart whiteboards are eased by the faculty members. However, the adoption and the implementation of these types of learning tools such as the smart whiteboards in the classrooms required top administrations support (Tosuntas, Karadag, \& Orhan, 2015).

In gathering feedback from faculty members, students, and administrators, DiVall et al. (2013) stated that $64 \%$ of faculty members of one college used various available classroom technology while claiming that using classroom technology enhanced teaching practices. In this study, faculty members reported changing their teaching practices to accommodate various technology to meet the students' needs; and students, on the other hand, reported overall satisfaction and positive feedback about the appropriateness of technology that was used throughout the classes. For example, active learning technology tools such as clickers were used to enhance teaching practices as well as to foster student engagement (Alharthi, 2020; Chan et al., 2016; Daniel \& Tivener, 2016; Wallace-Spurgin, 2018). In Chan et al. (2016) quantitative study that surveyed approximately 600 full and part-time faculty members, the results revealed that faculty members should try to test the technology before its adoption.

In an effort to determine factors that influenced faculty members to use classroom technology, Garner and Bonds-Raccke (2013) stated that four factors such as time, attitude, belief, and comfort level were present in studying faculty members' usage of technology. The results of the study indicated that those faculty members who received a formal training at the university level had higher levels of using classroom technology. While the study provided practical implications of faculty members' time, attitude, belief, and comfort levels, there was an indication that there is still more research to be done in finding out how to best influence teachers to integrate learning technology tools.

\section{Choosing a Fit Technology}

A general trend of overall views and perceptions of faculty members about the importance of implementing the smart whiteboards in the classrooms. The analysis of the research data suggested that the participants felt comfortable using technology. However, the use of these tools was associated with the fact that: a) these technology tools should not be uniformly imposed across diverse classrooms and b) faculty members' teaching practices often influenced decisions in using the learning technology tools.

\section{Overall Trends}

The participants not only commented on using their technical skills effectively but they also seemed to value use of any type of technology tools in the classrooms. The participants generally expressed a positive attitude toward the learning technology tools such as the Cisco Spark and Microsoft Surface Hub smart whiteboards:

\section{“...definitely going to the positive direction. The update of the classroom technology is going to the right} direction and definitely a trend." 
For a better understanding of the importance of the learning technology tools, one of the participants noted that these tools often provide more opportunities to improve student learning by having additional resources and information available to students. The readily information was helpful "during a class so they can make a use of the lecture." Others, for example, added that learning technology tools make teaching better and efficient.

They acknowledged that they would be able to effectively use those tools if they were available. For example, one participant described that it would definitely help him to "mix things up" during a class. Although, he stated that the new technology implementation process was not always smooth, he said: "I would prefer technology, but technology is not always available. So, it is okay for me."

\section{Classroom Fit}

Various views and opinions that were shared among the participants that using and implementing learning technology tools should not be developed and implemented as one unique strategy. Instead, it should be tailored to demands of different disciplines, class sizes, and students. The technology tools have a potential to change the teaching methods.

It was evident that some faculty members had the ability to move from the traditional methods of delivering lecturers to become an enabler to motivate their students in becoming active learners. For example, one participant explained that using learning tools could be helpful in presenting complex learning materials to the students and allowing the students to work independently. Another participant thought that new learning technology tools might be appropriate for some disciplines more than for others:

\section{"I'd highly recommend for science type classes."}

The instructional approach must be flexible enough to adjust the lecture in order to engage students' minds (Gilakjani, 2013). Class size was another factor that frequently came up during the discussions. A class size was an important consideration when choosing a technology for the classroom.

\section{Instructor Fit}

The relationship between faculty members' teaching approaches and the use of the learning technology tools, such as Cisco Spark and Microsoft Surface Hub smart whiteboards, is one of the factors that stood out from the data analysis. Faculty members' teaching styles and their teaching practices often influenced decisions about using classroom technology tools (Gilakhani, 2013). It was apparent from the conversations with the faculty members that the successful use of the learning technology tools in the classrooms was also affected by one's teaching experiences:

"I just think everybody should know what works best for them. It depends on person's personality $<\ldots>$ It depends on the instructor. You can really have a great class with a chalkboard and a horrible class with the smartboards; it all depends on the instructor or the content."

According to Gorder (2008), the teaching experience is directly related to the actual use of classroom technology. One participant stated that younger professors already come more skilled and proficient in using computer technology tools. He explained that the 'seasoned' professors are not focused on changing their pedagogical approaches because of the comfort level and the one's computer experience.

\section{Perceived Benefits}

The perceived benefits of to what extend using the smart whiteboards would help with the implementation of learning technology tools in the classrooms were really essential. 


\section{Student-related Benefits}

The participants' views on how the learning technology tools could benefit the students in the classroom. For instance, anonymity was one of the factors that arose from the discussions on being able to submit responses anonymously helped some students to participate in the class discussions. Most participants believed that, in contrast to the traditional classroom discussions, an opportunity to submit answers to the questions without a risk to be embarrassed in front of their peers promoted students' engagement.

Asking students to raise their hands can diminish learning by limiting the time to which a student engages (Levy, Yardley, \& Zeckhauser, 2017), enable the faculty members to effectively manage, particularly in larger size classes. Furthermore, several participants expressed a general sense that the use of learning technology tools helped to motivate and engage students. For example, one participant recognized that the use of the learning technology tools helped to engage the students:

"If I ask students to answer questions, if 10 students raise hands and I have 30 students in the class, I can't call every one of them to tell the answer..."

Another participant felt that the smart whiteboards might work for some students better than for others. He thought that a traditional way of teaching might be somewhat boring to students, because "that it's basically me speaking the entire time."

\section{Instructor-related Benefits}

The participants' views on how the learning technology tools would benefit them for instruction were also strong indicators of their planning, decisions, and classroom practices. One of the first important elements of these indicators, the participants talked about its potential content improvement and efficiency. Time saved by the use of the smart whiteboard can be used to connect with students and to explain the lecture in more depth. It also appeared that the smart whiteboards could help with creating instructional materials and saving them for the next day review of the material

The participants recognized that efficiency was an indicator how they viewed the benefits of the learning technology tools, one participant, for example, stated: "I like clickers because they are efficient. I can use [clickers] a lot because I know they can be simple and easy. [...] I like the idea that I get immediate response and immediate feedback." The participants' responses were clear about the potential benefits of using smartboards to increase students' learning experiences. Another advantage was in improving the flow of the lectures.

The research data showed that the participants appreciated the fact that the availability of new learning technology tools might have presented them with opportunities to improve and explore new ways of teaching. One participant said that utilizing technology-based learning tools is an effective approach to dramatically enhance the course materials. The faculty members have a unique responsibility to advance their students' critical and problem solving skills, as well as increase the students' understanding of the material.

Engaging students in critical reasoning and thinking requires a variety of creative techniques to enhance and adapt to the various learning needs of students (Reid \& Weber, 2008). Visual media, such as videos, have the advantage of being "easy" and accessible in most classroom environments. The smartboard technology come already equipped with interactive displays, making it 'easy' to use and incorporate to tailor to a class, that are designed to make learning engaging and interactive:

“...you can use it [smart whiteboard] with the apps. It is very interactive; teaching, editing, and this is what I want to do... Save it and screen shot it. And it is awesome 


\section{Perceived Barriers}

Understanding faculty members' perceptions of the potential barriers in using the tools can be a first step in developing strategies for helping them change the way they teach (Michael, 2010). While the participants pointed out the potential benefits of the learning tools, they were also concerned about: a) unforeseeable technical issues; b) the possible distractions that active learning technology tools could bring to the students; and c) faculty members' potential resistance to change.

\section{Unforeseeable Technical Issues}

Faculty members stated that new technologies often come with new technical issues that they also have to learn how to resolve them. They also believed that it is difficult to maintain a quality control of the class, as they cannot predict when the technical issues might arise. Another layer of issues reflects the faculty members' views of learning and the requirements it makes on them. The majority of the participants voiced a concern that when technology stops working for any unforeseeable reasons, they had to have a backup plan.

Faculty members perceived that they did not have sufficient technical skills to immediately resolve the technicalities and move on with the class. A few of them also felt that they would be doing things almost twice to deal with the technical issues. The most important concern was that because it takes too much time for preparation, that is if something breaks, they would need to spend time and effort to have a backup plan to teach in a traditional mode. Participants' technical difficulties could be problematic, but a few participants also noted that many instructors overuse the technology tools. One participant stated that they [faculty] simply put too much emphasis on it, by adding too many videos, pictures, animations, and graphics, "just for the sake of having something extra."

\section{Student-Related Issues}

Participants' views and perceptions about the potential barriers of learning technology tools included that classroom technology, in general, can be a distraction tool. The most common concern was that students get distracted easily and faculty need to keep their attention. One participant noted that some students try taking notes with iPads. While he did not notice any issue with that, the participant felt that the notepads could be a distraction to the students because they [students] could be checking their emails or checking their social media accounts.

Not very many students in the class sometimes respond to new technology in the classroom. Students do not usually know what to do and what to expect with classroom technology tools, and "they do not usually like it when they do it - at least initially" (Michael, 2010, p. 3). While this might be true in some classrooms, one participant was not sure if the tools are bringing a positive learning impact on students.

\section{Instructor-related Issues}

The participants voiced a concern that they have to learn to overcome the technical difficulties during course material preparation and teaching. While overcoming technical difficulties is definitely a contributing factor, the majority of the participants were not always encouraged in favor of using any new active learning technology tools available to them. Seven out of eight participants stated that using learning technology tools requires too much time and preparation. In particular, one participant said that using new technologies significantly increased the preparation time:

$$
\text { “...can be a little intimidating at first..." }
$$

One participant stated that the learning technology environment can be in any physical environment and they [faculty members] need to be creative and flexible to be successful. Finally, the other interesting comment about perceived barrier was what one participant said: "...if the smartboard has a disadvantage, it does tie you to the board. So, if there is a disadvantage, it's a minor." 


\section{Conclusion}

Overall, the participants agreed that the implementation of the learning technology tools in the classroom setting was beneficial to both students and the faculty members. However, as we explore the successful use of learning technology tools, it is important to assess that the implementation of these technologies should not be uniformly applied to the classrooms. Taking into account unique demands of different disciplines, classrooms, and teachers are clear. They believed that the smart whiteboards would have helped them to enrich the instructional process and make it more efficient. However, they also were clear that these benefits come with additional costs, such as extra preparation time, potential distraction to the students, and a necessity to deal with ongoing technical issues.

\section{References}

Akgun, F. (2017). Investigation of instructional technology acceptance and individual innovativeness of academicians. Turkish Online Journal of Qualitative Inquiry, 8(3), 291-31. http://dx.doi:10.17569/tojqi.292135

Alharthi, M. (2020). Students' attitudes toward the use of technology in online courses. International Journal of Technology in Education (IJTE), 3(1), 14-23.

Al-Qirim, N. (2016). An empirical investigation of smart board innovations in teaching in UAE university. Education and Information Technologies, 21(6), 1895-1911.

Chan, T. F. I., Borja, M., Welch, B., \& Batiuk, M. E. (2016). Predicting the probability for faculty adopting an audience response system in higher education. Journal of Information Technology Education, 15, 395407. https://doi.org/10.28945/3548

Cuhadar, C. (2014). Information technologies pre-service teachers' acceptance of tablet PCs as an innovative learning tool. Educational Sciences: Theory and Practice, 14(2), 741-753.

Daniel, T., \& Tivener, K. (2016). Effects of sharing clickers in an active learning environment. Journal of Educational Technology \& Society, 19(3), 260-268.

Davis, F. (1989). Perceived usefulness, perceived ease of use, and user acceptance of information technology. MIS $\quad$ Quarterly, $13(3), \quad 319-340 . \quad$ Retrieved https://www.jstor.org/stable/pdf/249008.pdf

Day, M., Demiris, G., Oliver, P., Courtney, K., \& Hensel, B. (2007). Exploring underutilization of videophones in hospice settings. Telemedicine and e-Health, 13(1): 25-32. https://doi.org/10.1089/tmj.2006.0023

DiVall, M. V., Hayney, M. S., Marsh, W., Neville, M. W., O’Barr, S., Sheets, E. D., \& Calhoun, L. D. (2013). Perceptions of Pharmacy Students, Faculty Members, and Administrators on the Use of Technology in the Classroom. American Journal of Pharmaceutical Education, 77(4), 1-7.

Dube, S. (2017). Educators' pedagogical concerns on blending ICTs in teaching. Proceedings of the European Conference on E-Learning, 150-155.

Garner, A., \& Bonds-Raacke, J. (2013). Influence of university level direct instruction on educators' use of technology in the classroom. Reading Improvement, 50 (4), 145-157.

Gilakjani, A. (2013) Factors contributing to teachers' use of computer technology in the classrooms. Universal Journal of Educational Research. 1(3), 262-267. DOI: 10.13189/ujer.2013.010317

Gorder, L. (2008). A study of teacher perceptions of instructional technology integration in the classroom. Delta Pi Epsilon Journal, 50(2), 63-76.

Holden, R. J., \& Karsh, B.T. (2010). The technology acceptance model: its past and its future in health care. Journal of Biomedical Informatics, 43(1), 159. http://doi.org/10.1016/j.jbi.2009.07.002

Hoppe, U., Steinhüser, M., \& Vogelsang, K. (2013). A qualitative approach to examine technology acceptance. ICIS

Ifenthaler, D., \& Schweinbenz, V. (2016). Students' acceptance of tablet PCs in the classroom. Journal of Research on Technology in Education, 48(4), 306-321. https://doi.org/ 10.1080/15391523.2016.1215172

Karsh, B., Escoto, K., Beasley, J., \& Holden, R. (2006). Toward a theoretical approach to medical error reporting system research and design. Applied Ergonomics, 37(3), 283-295. http://doi.org/10.1016/j.apergo.2005.07.003

Khalil, S. M. (2013). From resistance to acceptance and use of technology in academia. Open Praxis, 5(2), 151163.

Levy, D., Yardley, J., \& Zeckhauser, R. (2017). Getting an honest answer: Clickers in the classroom. Journal of the Scholarship of Teaching and Learning, 17(4), 104-125. https://doi.org/https://doi.org/10.14434/josotl.v17i4.22068

Michael, J. (2010). Faculty perceptions about barriers to active learning. College Teaching, 55(2), $42-47$. doi:10.3200/CTCH.55.2.42-47 
Middlemass, J., Vos, J., \& Siriwardena, A. (2017). Perceptions on use of home telemonitoring in patients with long term conditions - concordance with the Health Information Technology Acceptance Model: A qualitative collective case study. BMC Medical Informatics \& Decision Making, 171-13. https://doi.org/10.1186/s12911-017-0486-5

Ouadahi, J. (2008). A qualitative analysis of factors associated with user acceptance and rejection of a new workplace information system in the public sector: a conceptual model. Canadian Journal of Administrative Sciences, 25(3), 201-213.

Park, J. (2014). Pre-service and in-service teachers' perceptions toward white board system prior to actual experience. Universal Journal of Educational Research, 2(3), 262-270.

Reid, L. A., \& Weber, C. M. (2008). Using technology-enabled active learning tools to introduce business ethics topics in business law courses: A few practical examples. Journal of Legal Studies Education, 25(2), 283-305.

Sahin, I. (2008). From the social-cognitive career theory perspective: A college of education faculty model for explaining their intention to use educational technology. Journal of Educational Computing Research, 38(1), 51-66.

Sahin, I., \& Thompson, A. (2007). Analysis of predictive factors that influence faculty members technology adoption level. Journal of Technology and Teacher Education, 15(2), 167-190.

Salmona, M., \& Kaczynski, D. (2016). Don't blame the software: Using qualitative data analysis software successfully in doctoral research. Forum: qualitative social research, 17(3), 42-64. http://dx.doi.org/10.17169/fqs-17.3.2505

Sarker, S., \& Wells, J.D. (2003). Understanding mobile handheld device use and adoption. Communications of the ACM, 46(12), 35-40.

Serhan, D. (2019). Web-Based Homework Systems: Students' Perceptions of Course Interaction and Learning in Mathematics. International Journal on Social and Education Sciences, 1(2), 57-62.

Thomas, D. (2003). A general inductive approach for qualitative data analysis. American Journal of Evaluation, 27(2).

Tosuntas, S. B., Karadag, E., \& Orhan, S. (2015). The factors affecting acceptance and use of interactive whiteboard within the scope of FATIH project: A structural equation model based on the unified theory of acceptance and use of technology. Computers \& Education, 81, 169-178.

Wallace-Spurgin, M.R. (2018). Implementation of the instructional practices inventory-technology process with fidelity: The impact on technology use and student cognitive engagement. International Journal of Technology in Education (IJTE), 1(1), 35-45.

Weaver, A., Walker, H., \& Marx, A. (2012). Student and faculty perceptions regarding the use of technology in Sport Management coursework. Journal of Technology Integration in the Classroom, 4(3), 25-36.

Wu, P. (2012). A mixed methods approach to technology acceptance research. JAIS, 13(3), 172-187. 